\title{
nature
}

\section{Time to accept realities of bioweapon control}

The costs of preventing the barbarity of biological warfare are not only financial but also include intrusiveness, at home as well as abroad. There is an urgent need to shoulder those costs to ensure an effective ban.

T here will inevitably be a temptation to relax a little after what appears to have been the successful resolution of the latest confrontation with President Saddam Hussein of Iraq. If the agreement brokered by the UN Secretary-General, Kofi Annan, holds, the West can increase its confidence in the eventual destruction of Saddam's arsenal of chemical and biological weapons, while Saddam can offer his people the hope that such a move will lead to the lifting of economic sanctions. But relaxation would be a mistake. The Iraq crisis has been a stark reminder that, even though the use of such weapons is outlawed by two international treaties, the threat they represent remains very real.

It is therefore pleasing that President Bill Clinton has recently released a new statement of US policy that addresses one aspect of this threat, namely support for the speedy completion of a protocol to the Biological Weapons Convention of 1972, outlining how compliance with this convention might be monitored and verified (see page 831). Pressure for such a protocol has not come from the recent behaviour of Iraq alone; other countries have been arguing the case for several years, and have set in motion diplomatic negotiations which the United States has now agreed to join. But Saddam Hussein's actions have certainly focused minds in a way that few other events could have done.

The situation in Iraq has helped to clear the air in other ways too. Some of the traditional US scepticism about the value of verification procedures should have been tempered by the ingenuity and effectiveness displayed by United Nations weapons inspectors since the ending of the Gulf War in 1991. Those who had argued that such inspectors would be easily hoodwinked have had to eat their words. And the argument that a verification regime would make little impact has, in the process, lost much of its weight. The task facing those negotiating a draft protocol, with Clinton's support now ringing in their ears, is to design a regime that is rigorous, effective and trustworthy.

Formidable obstacles remain. The pharmaceutical and biotechnology industries, for example, both in the United States and elsewhere, have raised concerns - some legitimate, some possibly less so - about the potential threat to commercial confidentiality inevitably created by a visit by foreign inspectors. Other major powers, in particular Russia and China, as well as Japan, have to be persuaded to share the political enthusiasm of the West for strict controls. And countries from the poorer 'South' will expect some form of compensation for their support.

But none of these problems is insurmountable. Experience with the ChemicalWeapons Convention of 1993 has shown that it is possible to design inspection procedures that the industry does not find excessively burdensome or intrusive. All major governments must be sufficiently worried about the threat of terrorists releasing biological weapons onto their soil to wish to reduce the likelihood of that happening. And possible compensation schemes for the South — such as an international network to monitor emerging diseases - would not necessarily involve a massive transfer of either proprietary technology or intellectual property, two of industry's greatest fears.

The most difficult task will be to persuade Western nations to accept the costs involved, whether the relative loss of sovereignty implied by an international monitoring regime, the extra paperwork and regulations that would entail, or just the expense of an institutional apparatus designed to make it work effectively. But given terrifying scenarios that are now all too possible, those costs will be a small price to pay for the extra security they will buy.

\section{Cloning's confused signals}

\section{Worries about failure to replicate Dolly are premature but stimulating.}

T

here it was last week, in newspapers and, as follows, high up the CNN Web site: "The Scottish scientist credited with successfully cloning Dolly the sheep last year has admitted he may have made a procedural mistake... 'There is a remote possibility that the cell came from a fetus rather than an adult,' Ian Wilmut said...." Recently in Science, an attack on the original Nature paper met with a rebuttal from the original authors. But has the public been misled?

No more than in any significant but scientifically controversial development. One controversy concerns the burden of proof. How burdensome must it be, in an area where experiments are both timeconsuming and complex? With hindsight (and few could have anticipated the extent of the fuss stimulated by Dolly), it is always easy to claim that the proof was inadequate. But the definition of the threshold of proof is itself controversial, particularly given the significance that the results have taken on. According to soundings across the relevant research community (see page 825 ), the published attack represents an extreme position in its demands for proof. And according to encouragingly many, the probability that the paper's results are valid remains high. But this case is yet another illustration of the truism that a formal scientific publication need not necessarily be the last word.

In the meantime, the journals give formalized expression to the buzz of gossip and debate within the community. That debate, as it seeps out, can undermine in the public eye even the most rigorously justified claim. Yet whatever the risks for public perception, it is important that the plurality of scientific views is expressed in the open - which is where informal opinion in news and correspondence pages or on the Web plays its valuable part. It is also important that the public should recognize the current debate for what it is: scientists behaving critically, as they should. Most importantly, it is premature to draw any conclusions from the absence so far of a second mammal cloned from adult cells. 